\title{
The Potent of Carrier Oil on Pretreatment of Crude Jatropha Curcas Oil
}

\author{
Dini Kurniawati ${ }^{a}$, lis Siti Aisyah ${ }^{b}$ \\ a,b Program Studi Teknik Mesin \\ Universitas Muhammadiyah Malang \\ Jl. Raya Tlogomas no 246 Malang \\ e-mail: dini@umm.ac.id
}

\begin{abstract}
Jatropha curcas oil is a seed oil or bio-oil, which has advantages compared to others plant's seed-oil. The advantage of this oil is due to the fact that Jatropha oil does not compete with the food sector. In this research, the potential carrier oil testing was conducted to seek a way in improving the performance of Jatropha oil as lubricant oil, coolant or biodiesel. For this purpose, Jatropha oil was mixed with the other carrier oils in the variation of $0-45 \%$. Each variation was tested to obtain kinematic viscosity and density values. The results of this research was the carrier oils has the potential to be used as the mixing material since it can improve the physical properties of Jatropha oil, before the next process. Kinematic viscosity and density of Jatropha oil decreases as more percentage of mixed carrier oil was added.
\end{abstract}

Keywords: jatropha oil; kinematic viscosity; density; carrier oil

\section{INTRODUCTION}

Jatropha curcas plants is an ideal raw material for biodiesel, lubricant oil or coolant, because these plants do not compete with the food industry, and higher oil content compared to palm-oil. Jatropha oil content range from $32-35 \%$, whereas palm-oil is around $24 \%$. Jatropha curcas plants are easy to cultivate eventhough the productivity depends on several factors such as variety, soil fertility, soil texture, with the most important factors to consider are drainage system, rainfall and altitude [1].

Jatropha curcas oil has potential to be reprocessed, such as for biodiesel or lubricants. It is a renewable fuel that contains $10-12 \%$ more oxygen and its properties are closer to diesel [2]. Biodiesel itself is an alternative fuel that can be used as an additive for diesel oil derived from fossil. Biodiesel is now widely processed using the transterification reaction to produce methyl esther and glycerrin [3]. Conversion of triglycerides into esters is intricate, if vegetable oils consist of large amounts of FFA $(>1 \% \mathrm{w} / \mathrm{w})$ that will form soap with base catalyst [4]. Few researchers have worked with feedstocks having higher FFA levels using alternative processes [5].

Now the biodiesel is one of the alternative fuel and almost every country making a policy of using biodiesel in the transportation sector. Moreover, the scientific research on biodiesel production, storage, performance and emission has increased exponentially [6]. The important physical properties of biodiesel are kinematic viscosity, density and calorific values, where these properties greatly affect engine performance and emission [7]. In the process of making biodiesel, viscosity and density are two important physical properties that are widely used in combustion modelling and fuel quality [8][9].

In this research, Jatropha curcas oil has been tested for physical properties, especially kinematic viscosity and density after being mixed with various carrier oil. This treatment is expected to show the potential of carrier oil as a pretreatment for the process of making biodiesel [10]. So that biodiesel has been obtained is in accordance with the international standard of biodiesel. 


\section{Methods}

\subsection{Equipment and Materials}

This research used several equipment, namely glass bottle, specimen bottle, pycnometer, Ostwald viscometer, refrigerator and oven. Whereas the material used is crude Jatropha oil (CJO). The Jatropha curcas oil is obtained from the Faculty of Agriculture and Animal Husbandry, University of Muhammadiyah Malang. Olive oil and sunflower seed oil as a carrier oil and phosphoric acid $\left(\mathrm{H}_{3} \mathrm{PO}_{4}\right)$ as gum binder in the degumming process.

\subsection{Procedure}

\subsubsection{Preparation}

Jatropha curcas oil was obtained from the process of pressing Jatropha seed. After the process, the oil was precipitated to remove impurities for about 3 days. Then the deposition process take place, followed by oil filtering to produce pure Jatropha oil.

\subsubsection{Production}

Pure oil obtained from filtering process, then tested for the kinematic density and viscosity values. It was conducted to determine the initial density and viscosity of Jatropha oil. The next process was mixing and blending of Jatropha curcas oil with the carrier oil in the determined percentage. The oil mixture then mixed perfectly using a magnetic stirrer for about 15 minutes. Followed by degumming process using an operating temperature $80^{\circ}$ $\mathrm{C}$ in 30 minutes. After degumming process, the mixture oil then be allowed to settled and filtered to separate gum and oil for at least 48 hours. Oil that has been separated from gum, then purified using warm water around $55^{\circ} \mathrm{C}$ and separated again to formed 2 phases, water and oil. Separated oil then be heated in an oven at $90^{\circ} \mathrm{C}$ for about 2 days, or until the oil mass was stabilized.

\subsubsection{Testing}

After the degumming process, Jatropha oil was obtained which is free of gum. The next step was to re-measure the kinematic density and viscosity of the pure oil. Each concentration was measured using a $25 \mathrm{ml}$ pycnometer and measured at $20^{\circ} \mathrm{C}$.

After measuring the density at each concentration, kinematic viscosity measurements were carried out using an Oswald viscometer at $40^{\circ} \mathrm{C}$. Both values are theoretically adjusted to the density and viscosity value of the mixture.

\section{Result ANd Discussion}

Jatropha oil is one of the oil plants that have many advantages. The oil content that is above $40 \%$ with the highest fatty acid content is $45 \%$ oleic fatty acid [11]. Jatropha oil contains about $14 \%$ free fatty acids (FFA) which far exceeds the FFA level limit of $1 \%$ which can be converted to biodiesel using the transesterification reaction process with a base catalyst [12]. For this high level of FFA, it is necessary to optimize the process of converting Jatropha oil into biodiesel. The step that needs to be taken into account is the pretreatment at the beginning of the process to reduce high FFA levels to less than $1 \%$ in the transesterification reaction with a basic catalyst [13].

Carrier oils used in this study were extra virgin olive oil (EVOO) and sunflower seed oil (SFO). The two oils were chosen as carrier oils because the kinematic viscosity value of the two oils was lower when compared with Jatropha oil or crude jatropha oil (CJO). The kinematic viscosity of olive oil and sunflower seed oil are 29.4 and $34.4 \mathrm{cSt}$, respectively [14].

\subsection{Effect of Carrier Oil Concentration to Kinematic Viscosity}

Viscosity is usually defined as the time of volume of liquid flowing through the Oswald viscometer calibrated at $40^{\circ} \mathrm{C}$. Kinematic viscosity in biodiesel from plant oils has a very high value when compared to diesel fuel. This becomes the main problem in the combustion process.

Because fuels that have high viscosity will tend to form larger droplets during injection, resulting in worse atomization and creating problems such as crust in the combustion chamber [15]. 
Carrier oils used in this research are extra virgin olive oil and sunflower seed oil. The two oils were chosen as carrier oils because the kinematic viscosity value of the two oils is very low when compared with Jatropha oil or crude Jatropha oil (CJO). As a study conducted by Dermibas (2003) which states that the kinematic viscosity of olive oil and sunflower seed oil are 29.4 and $34.4 \mathrm{cSt}$, respectively.

The effect of carrier oil concentration on viscosity can be seen in Figure 1.

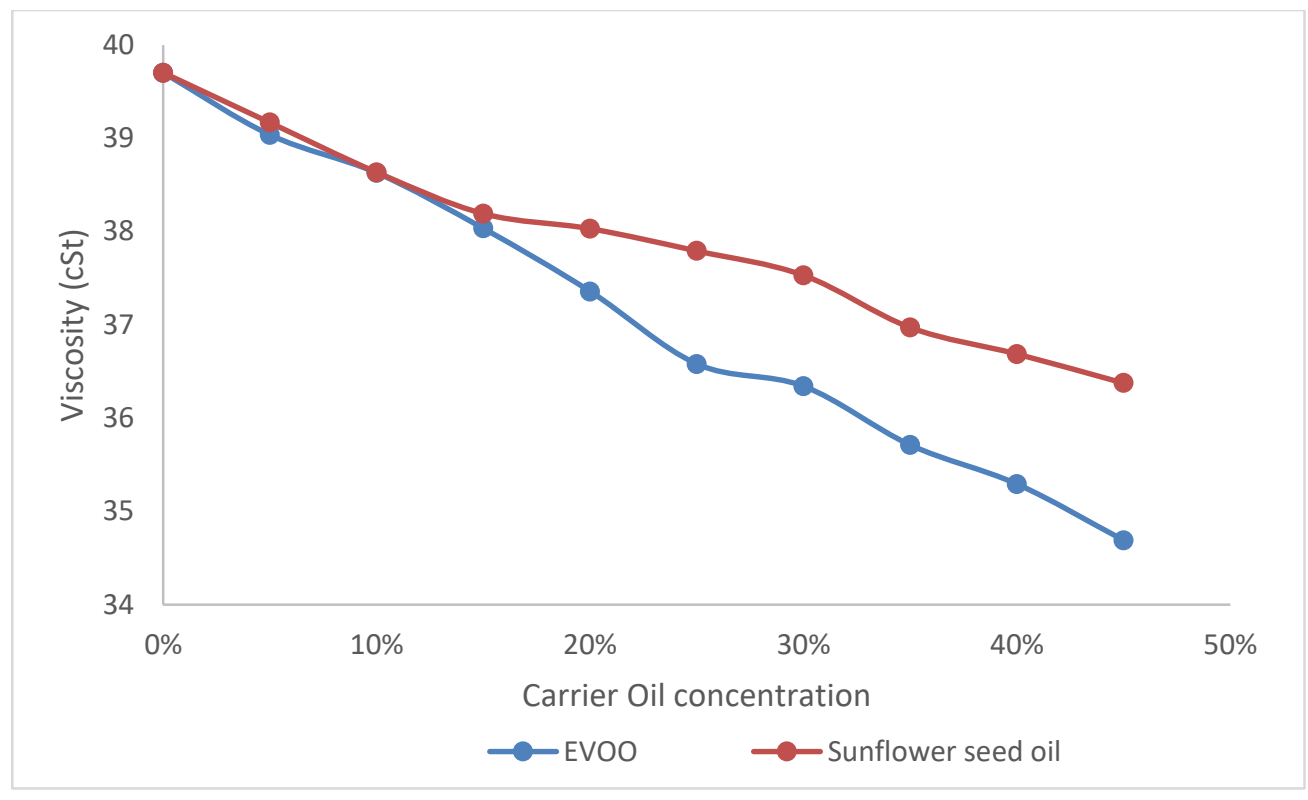

Figure 1. Relationship between carrier oil concentration and kinematic viscosity

In Figure 1 it can be seen that the concentration of carrier oil is very influential on kinematic viscosity. The kinematic viscosity of each oil used is mixed oil kinematic viscosity. In Figure 1, it can be seen that the kinematic viscosity for the addition of CJO with olive oil gives a lower viscosity value compared to the mixture of CJO with sunflower seed oil. This is because the kinematic viscosity value of olive oil is also lower when compared to sunflower seed oil.

Figure 1 also shows that CJO mixed with olive oil will give a low viscosity when processed through a transesterification reaction to be converted into biodiesel. This is shown from the performance graph that tends to be lowered compared to a mixture of CJO with sunflower seed oil. This is in line with the purpose of the transesterification process to reduce oil viscosity so that it can be used as an alternative diesel fuel as in previous research [16].

This study also compared kinematic viscosity values between testing with the theoretical one. Kinematic viscosity testing was conducted by using Oswald viscometer while theoretical kinematic viscosity was obtained from mixed kinematic viscosity for each concentration. The relationship between the two kinematic viscosity for mixture of Jatropha oil and olive oil (EVOO) can be seen in Figure 2.

From Figure 2, it can be seen that the kinematic viscosity of the oil mixture are not much different from the theoretical calculations. The more EVOO content given has the tendency to lower the kinematic viscosity. This can be estimated carefully because the kinematic viscosity of EVOO has a low value of $29.4 \mathrm{cSt}$ (Dermibas, 2003).

While the comparison of kinematic viscosity values of sunflower seed oil can be seen in Figure 3. 


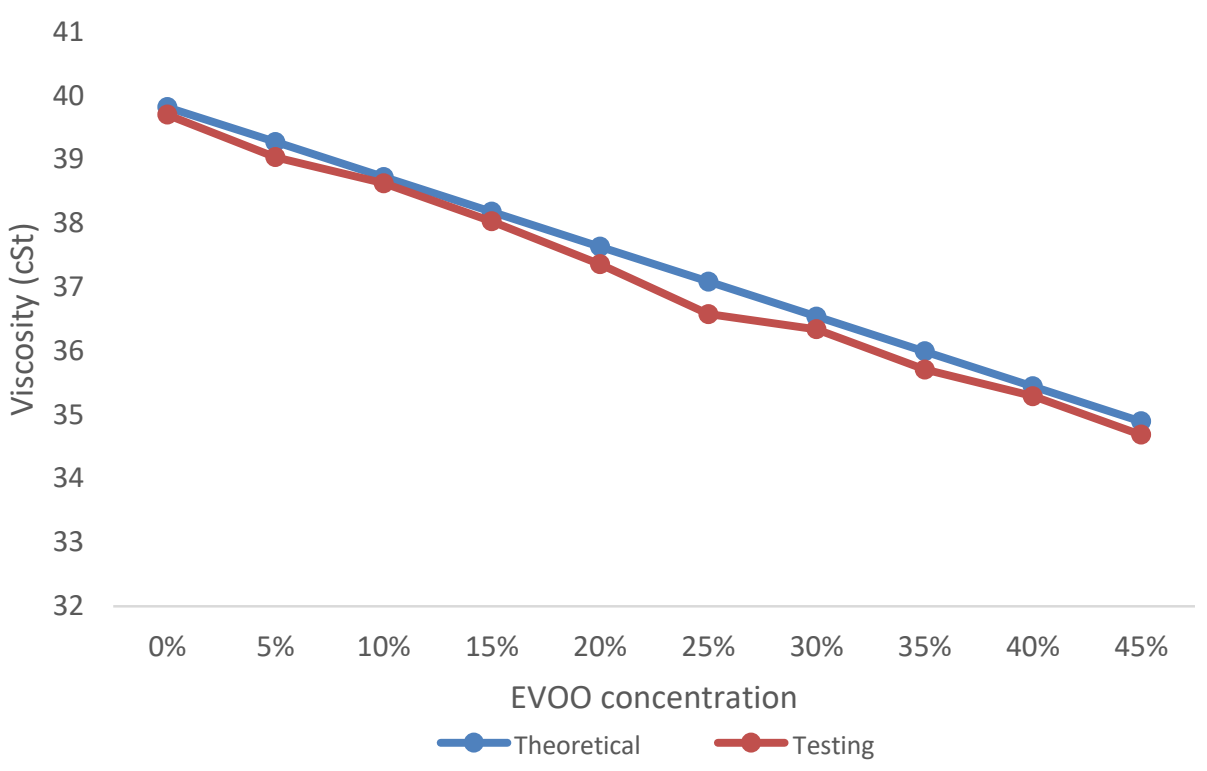

Figure 2. Relationship between EVOO concentration with theoretical and testing kinematic viscosity

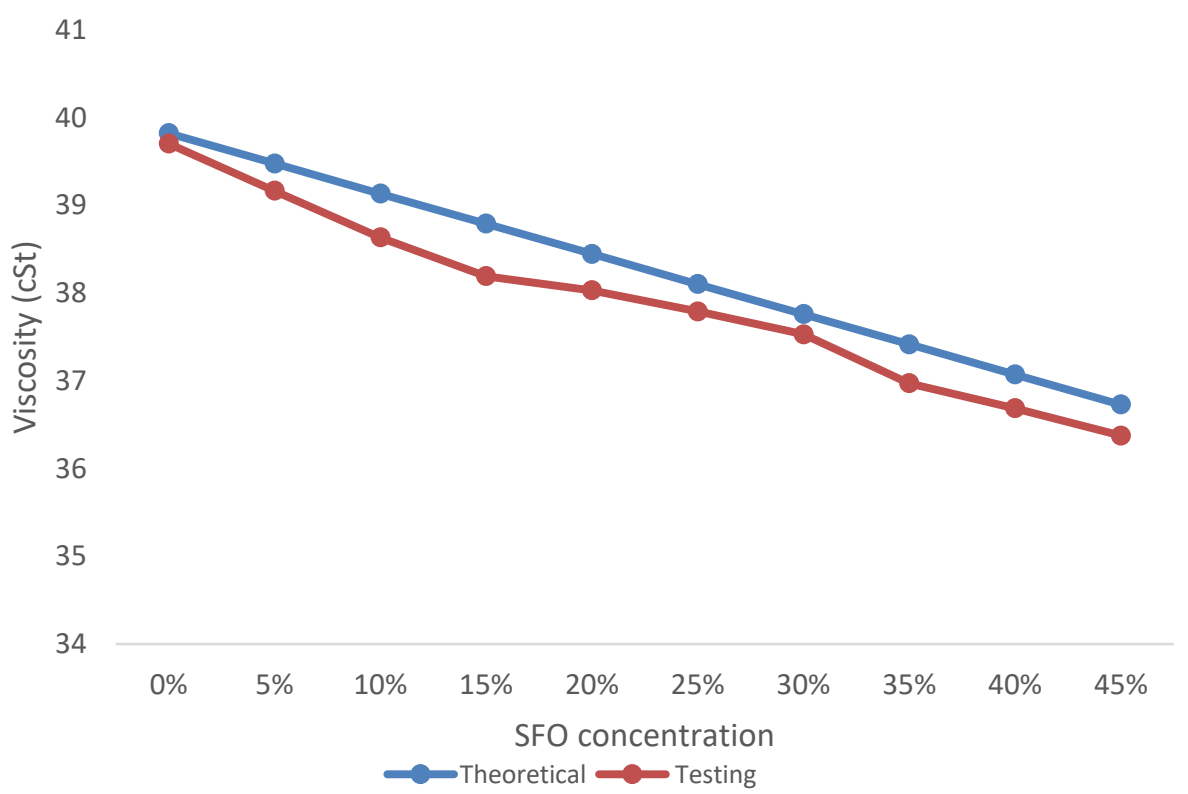

Figure 3. Relationship between SFO concentrations with kinematic viscosity theoretically and tested

In Figure 3 it can be seen that the kinematic viscosity of oil blends are not much different from the theoretical calculations. The more SFO content is given, the less likely is the kinematic viscosity to be lower. But the lowered value that occurred was not too large when compared to the decrease in EVOO. This is because the kinematic viscosity value of sunflower seed oil is much greater when compared to the kinematic viscosity of olive oil, which is $32.4 \mathrm{cSt}$ [14].

Kinematic viscosity is one of the most important things to know to determine the next step in the process of making Biodiesel. This is because the change in kinematic viscosity is one of the important specifications in accordance with ASTM-D445. This measurement step is important since high viscosity will cause poor atomization of the fuel spray so that it results in worsening the operation of the fuel injector [17]. 


\subsection{Effect of Carrier Oil Concentration on Density}

Density is another important thing in the process of making biodiesel. Density can be defined as the ratio of the mass of an object to its volume. This density is the density of a mixture of Jatropha oil (CJO) with carrier oil, namely sunflower seed oil and extra virgin olive oil. The effect of EVOO carrier oil concentration on density can be seen in Figure 4.

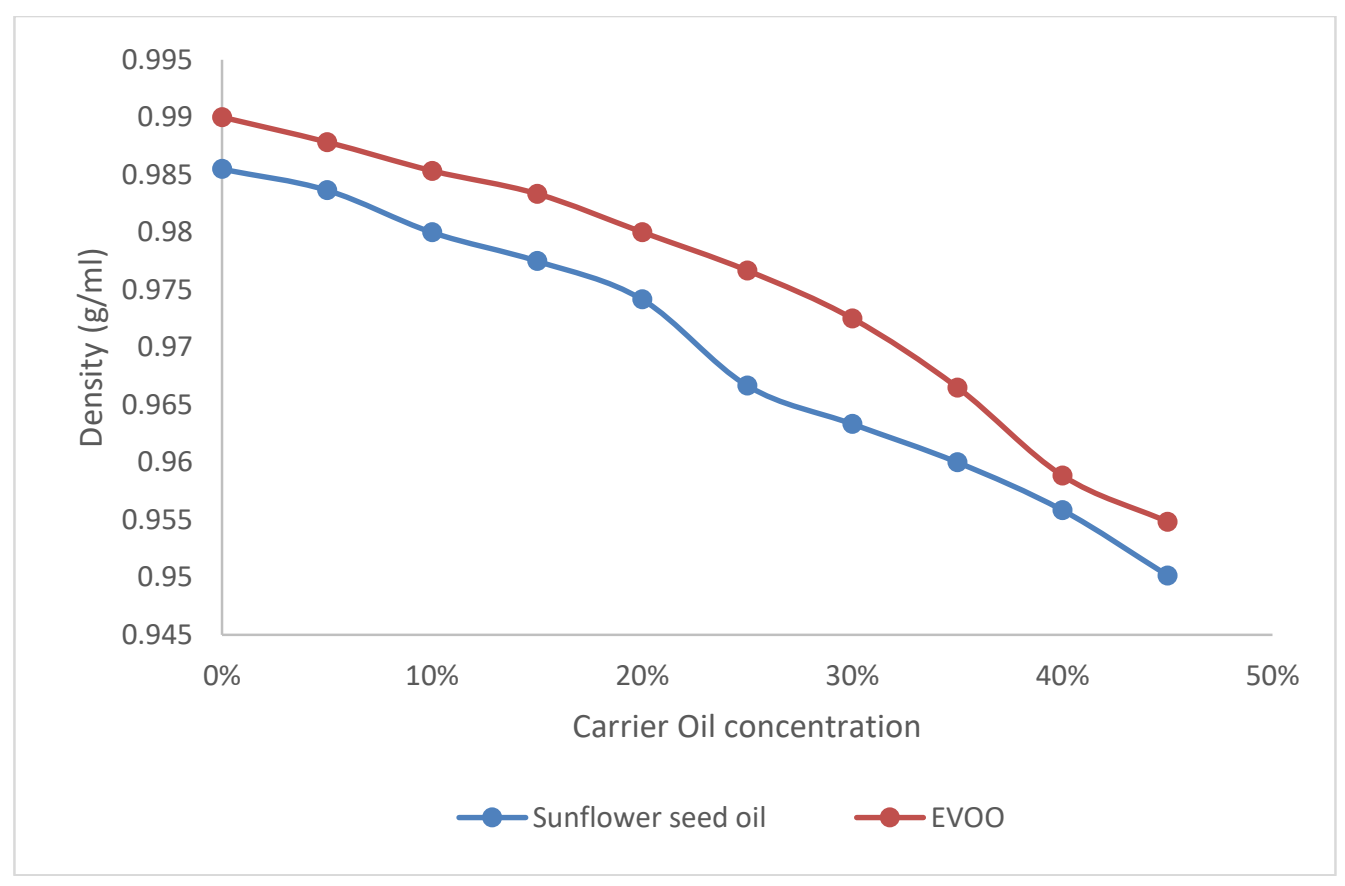

Figure 4. Relationship between carrier oil concentration and density

In Figure 4, it can be seen that higher the concentration of the carrier oil, the lower the density value. The density of sunflower seed oil is lower when compared to the density of extra virgin olive oil. But the densities of the three oil are actually very close, so the results of mixing using a pycnometer do not differ much.

The density of the mixed oils in this research is measured with a pycnometer at a temperature of $20^{\circ} \mathrm{C}$ in accordance with the specifications of the instrument used. The decrease in density at each concentration is due to the mixing between the two oils which have different densities in which one of them has a lower density because of the influence of the concentration of the carrier oil. This density measurement is carried out at the same temperature, so that there is no change in density as occurs when a temperature difference exist.

While the comparison of the density of pycnometer measurements with theoretical calculations of mixture density using EVOO can be seen in Figure 5.

In Figure 5, it can be seen that the density of the pycnometer measurement is lower when compared to the density of the calculated density results. This is because of effect of temperature instability when measuring with a pycnometer. The difference is around $0.3 \%$ $-1 \%$.

The comparison of the density of pycnometer measurements with theoretical calculations of mixture density using SFO can be seen in Figure 6.

In Figure 6, it can be seen that the density of the pycnometer measurement is lower when compared to the density of the calculated density results. This is because the influence of temperature instability when measuring with a pycnometer. The difference is around $0.7 \%-1 \%$. This change occurs due to differences in concentration variations and the number of double bonds found in EVOO and SFO oils. The double bonds contained in each carrier oil greatly affect the density of the mixture because the relative molecules of each carrier oil are also different [8]. 
JEMMME (Journal of Energy, Mechanical, Material, and Manufacturing Engineering) Vol. 5, No. 1, May 2020 | doi: $\underline{10.22219 / j e m m m e . v 5 i 1.12336 ~}$

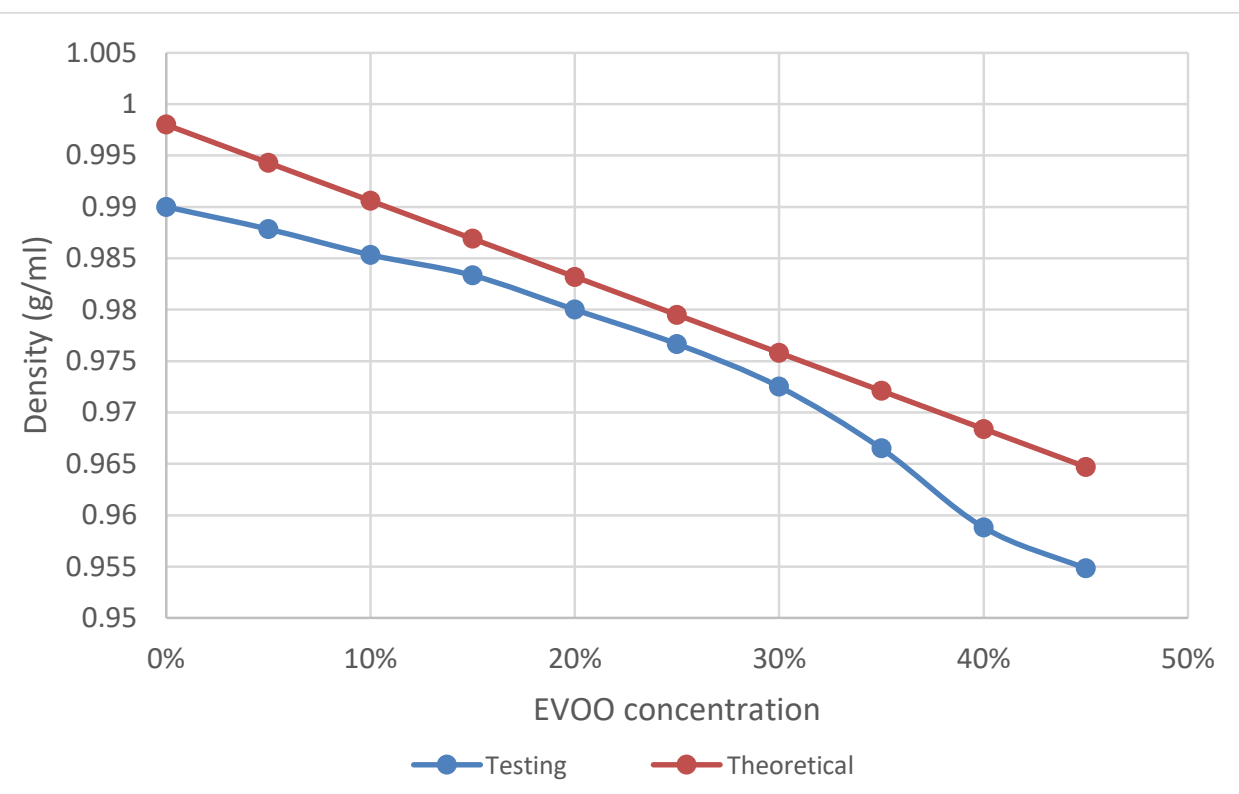

Figure 5. The relationship between EVOO concentration and density by means of experiments and calculations

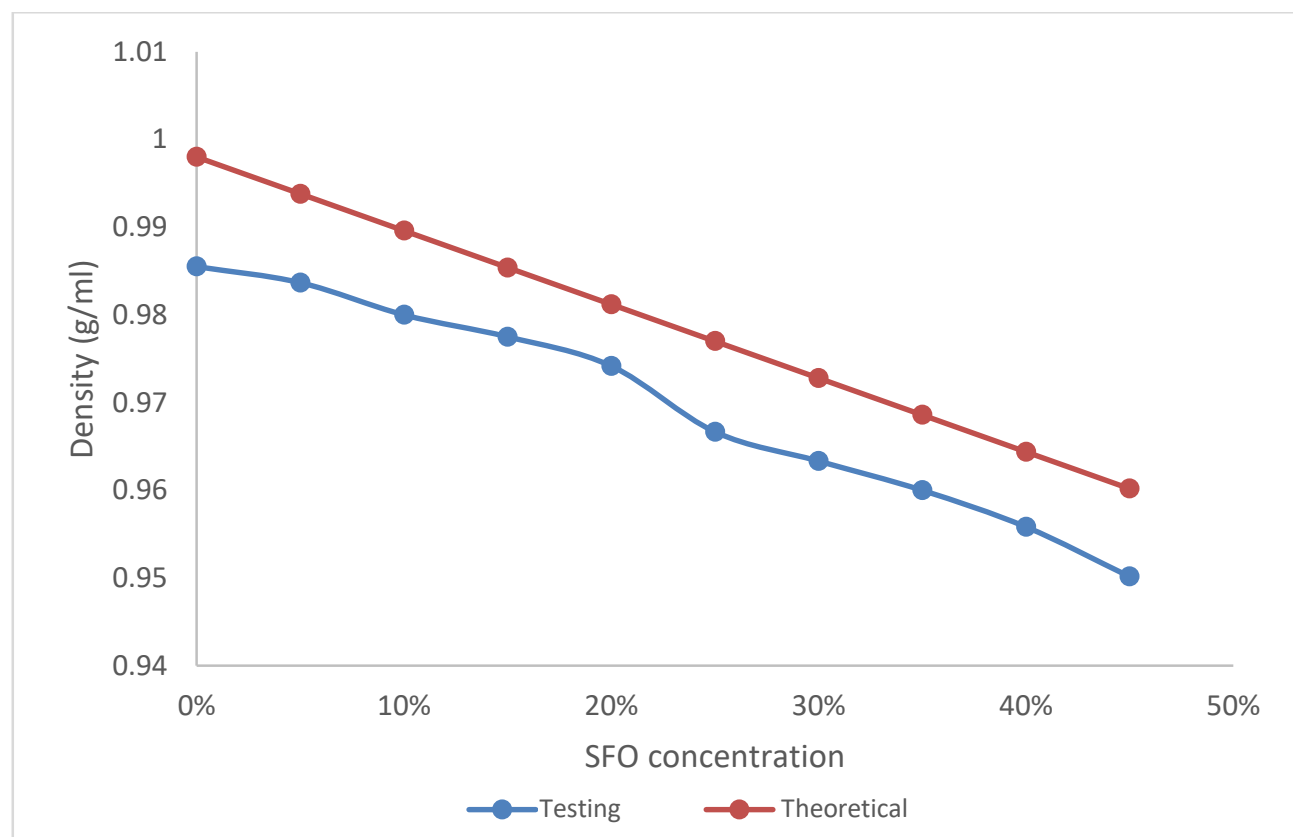

Figure 6. Relationship between EVOO concentration and density by experiment and calculation

This density measurement is needed to know the value of initial density of the mixture oil for making biodiesel. Once initial value is obtained then it can be estimated the density of produced biodiesel [7]. The decreasing density of this mixture will affect the density of biodiesel produced later. Because the density of biodiesel also affects the operation of fuel injection [18].

\section{ConClusion}

In this study the potential of carrier oil gives the result that EVOO and SFO have the potential to be used as carrier oil in the pre-treatment process of Jatropha Curcas oil as biodiesel. This is because the results of the viscosity and density of the mixture of CJO with the two oils that are used as carrier oil make the density and viscosity of CJO also decrease. 


\section{ACKNOWLEDGMENT}

The authors wish to thanks to the Ministry of Research Technology and Higher Education/Ristek-Dikti for financial support under grant PDUPT for the year of 2020 granted through University of Muhammadiyah Malang, Indonesia

\section{REFERENCES}

1. Mariam, S., Potensi Pengembangan Tanaman Jarak Pagar untuk Sumber Bahan Baku Biofuel. Makalah yang diseminarkan di Kalimantan Barat. 2006

2. Atabani, A.E., Badruddin, I.A., Masjuki, H.H., Chong, W.T., Mahlia, T.M.I., Lee, K.T., 2013. Investigation of physical and chemical properties of potential edible and nonedible feedstocks for biodiesel production. Renewable Sustainable Energy Rev., 2013; Vol. 21:749-75. https://doi.org/10.1016/..rser.2013.01.027

3. Pratas, M. J., Freitas, S., Oliveira, M. B., Monteiro, S. C., Lima, A. S. Coutinho, J. A. P. 2010. Densities and viscosities of fatty acid methyl and ethyl esters. Journal of Chemical and Engineering Data 2010; Vol. 55(9):3983-90. https://doi.org/10.1021/je100042c

4. Ma a, F., Hanna, M. A. 1999. Biodiesel production: a review. Bioresource Technology, 1999; Vol. 70(1):1-15. https://doi.org/10.1016/S0960-8524(99)00025-5

5. Dorado, M. P., Ballesteros, E., Almeida, J. A., Schellert, C., Löhrlein, H. P., Krause, R. An alkali-catalyzed transesterification process for high free fatty acid waste oils. American Society of Agricultural and Biological Engineers, 2002; Vol. 45(3):525-529. DOI:10.13031/2013.8849

6. Lapuerta M, Armas O, Herreros M., Effect of biodiesel fuels on diesel engine emissions. Progress in Energy and Combustion Science, 2008; Vol. 34:198-223. https://doi.org/10.1016/j.pecs.2007.07.001

7. Tesfa, Mishra, Gu, Powles, Prediction models for density and viscosity of biodiesel and their effects on fuel supply system in Cl engines. Renewable Energy, 2010; Vol. 35(12): 2752-2760. https://doi.org/10.1016/i.renene.2010.04.026

8. Verduzco, Luis F. P., Density and viscosity of biodiesel as a function of temperature: Empirical models. Renewable and Sustainable Energy Reviews, 2013; Vol. 19:652665. https://doi.org/10.1016/j.rser.2012.11.022

9. Knothe, G., Biodiesel and Renewable Diesel: A Comparison, Progress in Energy and Combustion Science, 2010; Vol. 36(3):364-373. https://doi.org/10.1016/j.pecs.2009.11.004

10. Van Gerpen, J., Shanks, B., Pruszko, R., Clements, D., Knothe, G., Biodiesel Production Technology, Subcontractor Report, National Renewable Energy Laboratory, US. 2004.

11. Foidl, N., Foidl, G., Sanchez, M., Mittelbach, M, Hackel, S., Jatropha Curas L. as a source for the production of biofuel in Nicaragua, 1996; Vol. 58(1):77-82. https://doi.org/10.1016/S0960-8524(96)00111-3

12. Tiwari, A.K., Kumar, A., Raheman, H., Biodiesel Production from jatropha oil (Jatropha Curcas) with high free fatty acid: An optimized process, Biomass and Bioenergy, 2007; Vol. 31(8): 569-575, https://doi.org/10.1016/i.biombioe.2007.03.003

13. Canakci M, Gerpen JV. Biodiesel production from oils and fats with high free fatty acids. American Society of Agricultural and Biological Engineers, 2001; Vol. 44(6):14291436. DOI: $10.13031 / 2013.7010$

14. Dermibas, A., Biodiesel Fuels From Vegetable Oils Via Catalytic And Non-Catalytic Supercritical Alcohol Transesterifications And Other Methods: A Survey. Energy Conversion and Management, 2003; Vol. 44:2093-2109, https://doi.org/10.1016/S0196-8904(02)00234-0

15. Freitas, S.V.D., Pratas, M. J., Ceriani, R., Lima, A.S., Coutinho, J.A.P., Evaluation of Predictive Models for the Viscosity of Biodiesel. Energy Fuels, 2010; Vol. 25(1):352358. https://doi.org/10.1021/ef101299d

16. Sajjadi, B., Raman, A.A.A., Arandiyan, H., A comprehensive review on properties of edible and non-edible vegetable oil-based biodiesel: Composition, specifications and prediction models. Renewable and Sustainable Energy Reviews, 2016; Vol. 63:62 92. https://doi.org/10.1016/i.rser.2016.05.035 
JEMMME (Journal of Energy, Mechanical, Material, and Manufacturing Engineering)

Vol. 5, No. 1, May 2020 | doi: $\underline{10.22219 / \text { iemmme.v5i1.12336 }}$

17. Graboski, M.S., McCormick, R.L., Combustion of fat and vegetable oil derived fuels in diesel engines, Progress in Energy and Combustion Science, 1998; Vol. 24(2):125164. https://doi.org/10.1016/S0360-1285(97)00034-8

18. Dermibas, A. Relationships derived from physical properties of vegetable oil and biodiesel fuels. Fuel, 2008; Vol. 87(8-9):1743-1748. https://doi.org/10.1016/j.fuel.2007.08.007 